\title{
Alunos com Altas Habilidades/Superdotação e o Atendimento Educacional Especializado
}

\author{
High Abilities Students/Gifted and the Specialized Educational
}

Assistance

\section{Alumnos con Altas Habilidades/Superdotación y el Atendimiento Educacional Especializado}

\author{
Vitória de Araujo Zanchetti \\ https://orcid.org/0000-0002-7964-273X \\ Solange Franci Raimundo Yaegashi ${ }^{2}$ \\ https://orcid.org/0000-0002-7666-7253 \\ Sharmilla Tassiana de Souza ${ }^{3}$ \\ https://orcid.org/0000-0002-9832-4745
}

Resumo: Como integrantes do público alvo da educação especial, os estudantes com Altas Habilidades/Superdotação têm direito ao atendimento educacional especializado. Nesse sentido, o presente artigo tem como objetivo analisar o estado do conhecimento sobre o trabalho desenvolvido nas Salas de Recursos Multifuncionais e nos Núcleos de Atividades de Altas Habilidades/Superdotação. Para tanto foi realizada uma pesquisa bibliográfica, buscando analisar as teses e dissertações publicadas na base de dados da Biblioteca Digital Brasileira de Teses e Dissertações do Instituto Brasileiro de Informação em Ciência e Tecnologia (BDTD/IBICT), no período entre 20II a 2020. Os resultados revelam que o trabalho desenvolvido no AEE enfrenta muitos desafios, como: dificuldades na identificação desses discentes, o não cumprimento das políticas públicas, infraestrutura precária e formação deficitária dos profissionais que atuam com este público. Concluímos que apesar das dificuldades, este atendimento se mostra de suma importância a este alunado.

Palavras-chave: Educação Especial. Altas Habilidades/Superdotação. Atendimento Educacional Especializado.

\footnotetext{
' Graduada em Pedagogia pela Universidade Estadual de Maringá. E-mail: vitoriazanchetti@gmail.com

${ }^{2}$ Doutora em Educação pela Universidade Estadual de Campinas. Professora do Departamento de Teoria e Prática da Educação, do Programa de Pós-Graduação em Educação e do Mestrado Profissional em Educação Inclusiva da Universidade Estadual de Maringá. E-mail: sfryaegashi@uem.br
}

3 Mestranda em Educação pela Universidade Estadual de Maringá. Professora da rede privada. E-mail: sharmilla.tsouza@gmail.com

Olhar de professor, Ponta Grossa, v. 24, p. I-22, e-18288.086, 2021.

Disponível em <https://revistas2.uepg.br/index.php/olhardeprofessor> 


\begin{abstract}
As members of the target audience of special education, students with High Abilities/Giftness (Altas Habilidades/Superdotação - AH/SD) are entitled to Specialized Educational Service (Atendimento Educacional Especializado - AEE). In this direction, this article aims to analyze the state of knowledge about the work developed in the Multifunctional Resource Rooms (Salas de Recursos Multifuncionais - SRM) and in the Centers for the High Skilled/Gifted Activities. For this purpose, bibliographic research was carried out, seeking to analyze the theses and dissertations published in the database of the Brazilian Digital Library of Theses and Dissertations of the Brazilian Institute of Information in Science and Technology (Biblioteca Digital Brasileira de Teses e Dissertações do Instituto Brasileiro de Informação em Ciência e Tecnologia - BDTD/IBICT) between 20II and 2020. The results reveal that the work developed at the AEE faces many challenges, such as difficulties in identifying these students, non-compliance with public policies, poor infrastructure, and deficient training of professionals who work with this audience. We conclude that, despite the difficulties, this service is of paramount importance to these students.
\end{abstract}

Keywords: Special Education. High Abilities/Giftness. Specialized Educational Service.

Resumen: Como integrantes del público meta de la educación especial, los estudiantes con Altas Habilidades/ Superdotación (AH/SD) poseen el derecho al Atendimiento Educacional Especializado (AEE). En ese sentido, el presente artículo tiene por objetivo analizar el estado de conocimiento sobre el trabajo desarrollado en las Salas de Recursos Multifuncionales (SRM) y en los Núcleos de Actividades de Altas Habilidades/Superdotación. Para eso se ha realizado una investigación bibliográfica, en la que se procura analizar las tesis y disertaciones publicadas en la base de datos de la "Biblioteca Digital Brasileira de Teses e Dissertações do Instituto Brasileiro de Informação em Ciencias e Tecnologia” (BDTD/IBICT), en el periodo entre el 20I I al 2020. Los resultados han revelado que el trabajo desarrollado en el $A E E$ encuentra muchos desafíos, como: dificultades en la identificación de esos discentes, el no cumplimiento de las políticas públicas, infraestructuras precarias y formación deficitaria de los profesionales que actúan con ese público. Hemos concluído que a pesar de las dificultades, ese atendimiento se muestra de gran importancia para ese alumnado.

Palabras-clave: Educación Especial. Altas Habilidades/Superdotación. Atendimiento Educacional Especializado.

\title{
Introdução
}

No Brasil, juntamente com as deficiências e os transtornos globais do desenvolvimento, as altas habilidades/superdotação integram a modalidade de ensino denominada "Educação Especial" de acordo com a LDB 9394/96 (BRASIL, 1996), sendo essa definição reafirmada nos demais documentos legais.

Por integrar este público-alvo, os alunos com AH/SD detém o direito ao acesso ao Atendimento Educacional Especializado (AEE), conforme determina o inciso III do Art. $4^{\circ}$ da resolução $n^{\circ}$ 4/2009 da Câmara de Educação Básica do Conselho Nacional de Educação, que apresenta como público alvo do AEE:

I - Alunos com deficiência: aqueles que têm impedimentos de longo prazo de natureza física, intelectual, mental ou sensorial.

II - Alunos com transtornos globais do desenvolvimento: aqueles que apresentam um quadro de alterações no desenvolvimento neuropsicomotor, comprometimento nas relações sociais, na comunicação ou estereotipias motoras. Incluem-se nessa definição alunos com autismo clássico, síndrome de Asperger, síndrome de Rett, transtorno desintegrativo da infância (psicoses) e transtornos invasivos sem outra especificação.

III - Alunos com altas habilidades/superdotação: aqueles que apresentam um potencial elevado e grande envolvimento com as áreas do conhecimento humano, isoladas ou combinadas: intelectual, liderança, psicomotora, artes e criatividade (BRASIL, 2009). 
Dessa forma, no que se refere às questões legais a respeito desse atendimento, somado à resolução $n^{\circ}$ 4/2009 da Câmara de Educação Básica do Conselho Nacional de Educação, tem-se o decreto $n^{\circ} 7.6 \mathrm{I} \mathrm{I/20} \mathrm{I} \mathrm{I} \mathrm{(BRASIL,} \mathrm{20} \mathrm{I} \mathrm{I)} \mathrm{que} \mathrm{reafirma} \mathrm{o} \mathrm{compromisso} \mathrm{do} \mathrm{Estado} \mathrm{com} \mathrm{o} \mathrm{AEE} \mathrm{na} \mathrm{Educação}$ Especial, delineando seu funcionamento.

O AEE está previsto em diversos documentos legais, dentre eles o inciso III do Art. 208 da Constituição Federal, no inciso III do Art. $4^{\circ}$ da LDB $9394 / 96$ e no Art. $5^{\circ}$ da resolução $n^{\circ}$ 4/2009 da Câmara de Educação Básica do Conselho Nacional de Educação (BRASIL, 2009), o qual dispõe que este serviço deve ser preferencialmente realizado nas Salas de Recursos Multifuncionais (SRM), da própria escola, ou outra escola de ensino regular, de forma a poder ser realizada em outras instituições sem fins lucrativos com o governo.

Frente à necessidade deste atendimento especializado, Virgolim (20I3, p.5I) apresenta que a identificação desses alunos se trata de um dos "[...] um dos pontos mais críticos e importantes [...]". Nessa perspectiva expõe que todos indiferente às condições financeiras, timidez, raça, língua, cultura, gênero, deficiência ou incapacidade, devem ter a oportunidade de desenvolver suas habilidades, sendo o conhecimento na área meio de diminuir a chance de excluí-los.

Nesse cenário, Rech $(2018$, p.160) destaca que muitas vezes a falta de conhecimento acerca das características e particularidades destes discentes por parte da escola, ao realizar o devido reconhecimento, especialmente nos casos dos alunos $\mathrm{AH} / \mathrm{SD}$, pode fazer com que passem "[...] invisíveis no sistema educacional". Frente a essa situação, a autora menciona que essa identificação é de extrema importância, quando se tem por meta a inclusão e não apenas a classificação.

Fleith (2007), ao discorrer sobre a temática, explica que é comum a crença entre professores e gestores de que o indivíduo com AH/SD deve se destacar em todas as áreas do conhecimento. Entretanto, ações mal planejadas da instituição acabam por influenciar no mau desempenho desses alunos e ainda há a visão de que não necessitam de um atendimento especializado para se desenvolver.

Nesse âmbito, Alencar e Fleith (2005) ressaltam que, pautadas em mitos que cercam as características dos alunos com $\mathrm{AH} / \mathrm{SH}$, as instituições escolares acabam se opondo à oferta de $\mathrm{AEE}$ a esses sujeitos, por acreditarem que não necessitam desse trabalho. A respeito desses mitos, Antipoff e Campos (2010) destacam que essas ideias errôneas acerca dos alunos com AH/SD são resultado da falta de conhecimento a respeito da realidade deste alunado.

Sobre esse atendimento, Alencar e Fleith (200I, apud FLEITH, 2007, p. 9) salientam que "[...] ○ aluno com altas habilidades/superdotação necessita de uma variedade de experiências de aprendizagem enriquecedoras que estimulem o seu desenvolvimento e favoreçam a realização plena de seu potencial”.

Olhar de professor, Ponta Grossa, v. 24, p. I-22, e-18288.086, 2021.

Disponível em <https://revistas2.uepg.br/index.php/olhardeprofessor> 
Dessa forma, Fleith (2007) evidencia que o atendimento a estes discentes deve ser baseado em seu desenvolvimento, contemplando o raciocínio crítico e criativo, de forma a auxiliar na manifestação do potencial desses sujeitos, bem como a autoconfiança e a persistência.

Nesse sentido, Corrêa e Delou (2016) afirmam que esse serviço pode ser ofertado em diferentes espaços, como a sala de aula, as Salas de Recursos Multifuncionais (SRM) e nos Núcleos de Atividades de Altas Habilidades e Superdotação (NAAH/S).

No que tange às SRM, Lima e Brandão (20I2) frisam que são destinadas a alunos matriculados em instituições públicas de ensino, de forma a contar com a atuação de professores com a devida formação, para ampliar o conhecimento dos alunos, em período de contraturno.

No que diz respeito aos NAAH/S, de acordo com seu Documento Orientador (BRASIL, 2006), foi implantado em 2005, sendo coordenado pela Secretaria de Educação Especial do Ministério da Educação, tendo como um de seus objetivos o atendimento aos alunos com $\mathrm{AH} / \mathrm{SH}$, além de prestar formações para professores nessa área. Todavia, Pérez e Freitas (20I I) mencionam que atualmente os Núcleos ainda em funcionamento, estão ligados às Secretarias Estaduais de Educação.

Analisando a formação acadêmica do pedagogo, nota-se que o enfoque majoritariamente é voltado aos estudantes com baixo rendimento escolar, de forma que a temática da $A H / S D$ não ganha a devida visibilidade. Com isso o trabalho se justifica pelo aprofundamento no tema, frente a necessidade da devida formação desse profissional, que não conhece as características desse alunado, não os compreende e não dispõe das condições necessárias para efetivar o desenvolvimento desses.

A respeito disso, Lima e Brandão (2012) apresentam que por se tratar de uma área de baixa evidência no Brasil, acabou-se por muito tempo sendo desprezada no cenário educacional, mesmo estando amparada por questões legais.

Diante disso, o presente trabalho tem como objetivo analisar, por meio de teses e dissertações, o estado do conhecimento sobre o trabalho desenvolvido no contexto das Salas de Recursos Multifuncionais e dos Núcleos de Atividades de Altas Habilidades e Superdotação, ofertados aos alunos com $\mathrm{AH} / \mathrm{SD}$.

Assim sendo, procurará investigar a problemática: Como as pesquisas stricto sensu apresentam - AEE ofertado a alunos altas habilidades/superdotação no contexto das salas de recursos multifuncionais e dos NAAH/S?

Foram analisadas as produções disponíveis na Biblioteca Digital Brasileira de Teses e Dissertações do Instituto Brasileiro de Informação em Ciência e Tecnologia (BDTD/IBICT), no período entre 201 I a 2020.

Para atingir a presente proposição, o artigo foi subdividido em três partes. Na primeira apresentamos a metodologia utilizada para a busca das teses e dissertações. Na segunda apresentamos

Olhar de professor, Ponta Grossa, v. 24, p. I-22, e-18288.086, 202 I.

Disponível em <https://revistas2.uepg.br/index.php/olhardeprofessor> 
os resultados e discussões, a qual envolveu a análise quantitativa e qualitativa dos materiais encontrados. E por fim, nas considerações finais, destacamos nossas percepções acerca da realização deste trabalho.

\section{Metodologia}

Para a realização do estudo realizamos uma pesquisa bibliográfica do tipo 'estado do conhecimento'. De acordo com Romanowski e Ens (2006), diferentemente das pesquisas do tipo 'estado da arte' que se propõe a estudar um tema pelo mapeamento de obras nos mais diversos setores de produção do conhecimento (livros, artigos, teses, dissertações, etc), o estado do conhecimento se dedica a apenas a um desses setores. Assim, no caso específico desse estudo, nos restringimos às produções stricto sensu desenvolvidas nos programas de pós-graduação do Brasil.

Por conseguinte, segundo Romanowski e Ens (2006, p.4I), esses tipos de pesquisas têm sua justificativa pautada na viabilização "[...] de uma visão geral do que vem sendo produzido na área e uma ordenação que permite aos interessados perceberem a evolução das pesquisas na área, bem como suas características e foco, além de identificar as lacunas ainda existentes."

Assim sendo, a busca das teses e dissertações que compuseram o corpus de nossa análise foi realizada na base de dados da Biblioteca Digital Brasileira de Teses e Dissertações do Instituto Brasileiro de Informação em Ciência e Tecnologia (BDTD/IBICT). O recorte temporal compreendeu o período de 201 I a 2020.

Como critério de inclusão, selecionamos apenas produções em língua portuguesa, que contemplavam o AEE destinado aos alunos com AH/SH, realizado nas SRM e nos NAAH/S. Como critério de exclusão, eliminamos os estudos que, embora se referissem aos alunos com AH/SD, não traziam detalhes sobre o AEE destinados a esses alunos.

Posto isso, no primeiro momento foi realizada uma busca na base de dados da BDTD por meio dos seguintes descritores: "Altas Habilidades Superdotação", "Atendimento Educacional" e "Sala de Recursos", combinados pelo operador booleano AND. Foram encontradas oitenta e nove (89) produções. Após análise realizada por meio da leitura dos títulos e resumos, foram selecionadas sete (7) publicações, as quais foram lidas na íntegra. Após a leitura detalhada, uma foi excluída, por não atender ao critério de inclusão definido para a pesquisa, de forma que restaram seis (6) delas que compuseram o corpus de nossa análise, conforme demonstrado na figura I.

Olhar de professor, Ponta Grossa, v. 24, p. I-22, e-18288.086, 2021.

Disponível em <https://revistas2.uepg.br/index.php/olhardeprofessor> 
Figura I - Fluxograma baseado na busca e seleção das publicações

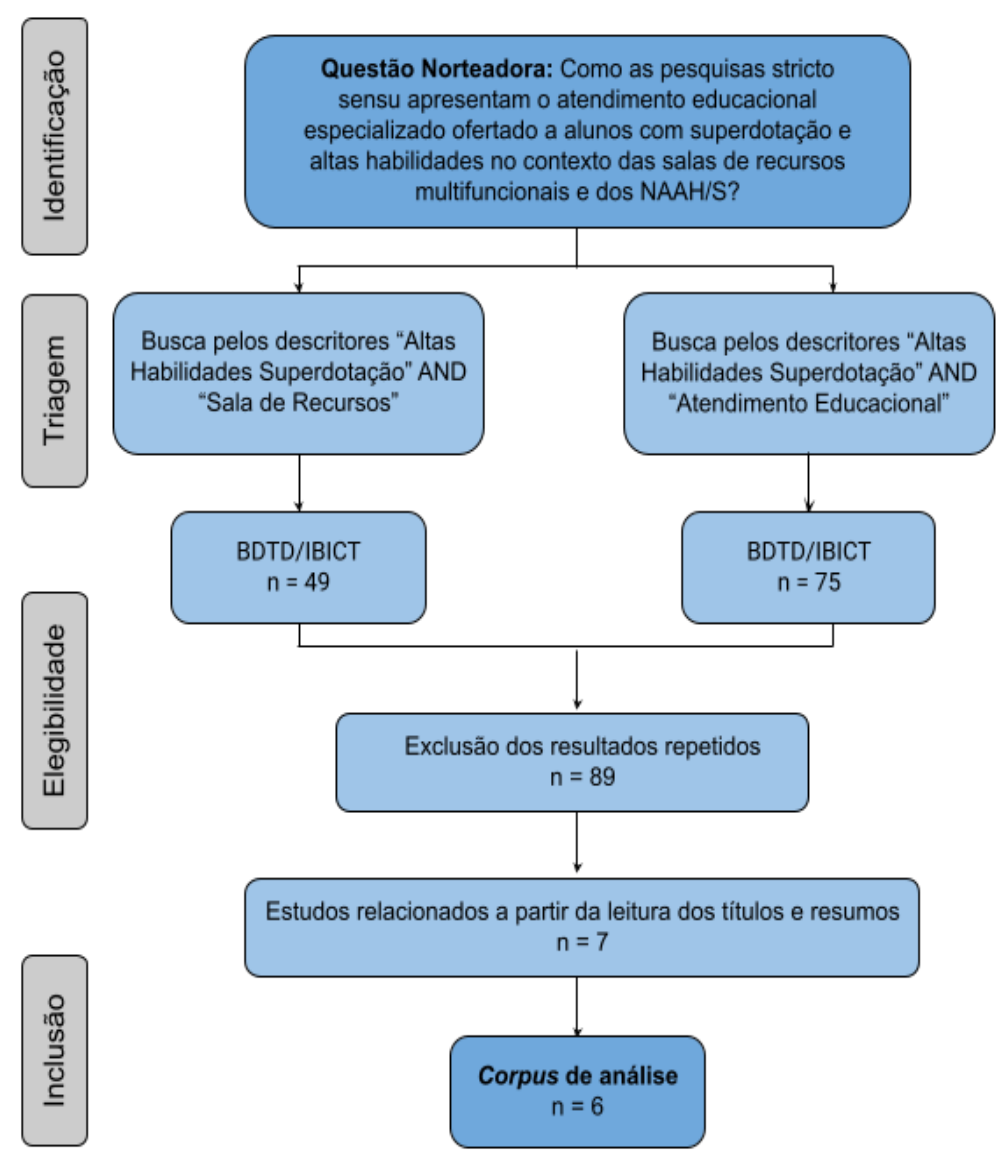

Fonte: Elaborado pelas autoras, com base no processo de seleção das publicações na base de dados BDTD/IBICT, 2020.

\section{Resultados e discussões}

Como forma de organização das seis publicações selecionadas, elaboramos um quadro (Quadro I), reunindo informações sobre ano e local de publicação, autores, títulos, tipo de pesquisa, objetivo e procedimentos metodológicos das produções a serem analisadas. 
Quadro I: Resultado da busca de referências a respeito do AEE para alunos com superdotação/altas habilidades no período de $201 \mathrm{I}$ a 2020

\begin{tabular}{|c|c|c|c|c|c|}
\hline $\begin{array}{c}\text { Ano/Local } \\
\text { de } \\
\text { Publicação }\end{array}$ & Autores & Título & Pesquisa & Objetivo & $\begin{array}{l}\text { Procedimentos } \\
\text { Metodológicos }\end{array}$ \\
\hline $\begin{array}{l}\text { 0II } \\
\text { Porto } \\
\text { Alegre/ } \\
\text { RS }\end{array}$ & $\begin{array}{l}\text { FERNANDES, } \\
\text { Gicele Sucupira }\end{array}$ & $\begin{array}{l}\text { "Entre uma sala } \\
\text { e outra: uma } \\
\text { experiência } \\
\text { etnográfica a } \\
\text { partir das salas } \\
\text { de recursos } \\
\text { para altas } \\
\text { habilidades/ } \\
\text { Superdotação } \\
\text { em Porto } \\
\text { Alegre, Rio } \\
\text { Grande do Sul" }\end{array}$ & Dissertação & $\begin{array}{l}\text { O objetivo do } \\
\text { presente } \\
\text { trabalho trata } \\
\text { de apresentar a } \\
\text { emergência do } \\
\text { alunado com } \\
\text { AH/SD como } \\
\text { integrantes do } \\
\text { público da } \\
\text { Educação } \\
\text { Especial. }\end{array}$ & $\begin{array}{l}\text { Participaram da } \\
\text { pesquisa } \\
\text { professores, alunos } \\
\text { e pais de } 8 \text { salas de } \\
\text { atendimento } \\
\text { educacional } \\
\text { especializado das } \\
\text { escolas da capital } \\
\text { gaúcha, sendo } 7 \\
\text { estaduais e l } \\
\text { municipal. Como } \\
\text { instrumentos de } \\
\text { coleta de dados } \\
\text { foram utilizadas } \\
\text { entrevistas e } \\
\text { observações. }\end{array}$ \\
\hline $\begin{array}{l}2013 \\
\text { Londrina/PR }\end{array}$ & $\begin{array}{l}\text { LYRA, Juliana } \\
\text { Chueire }\end{array}$ & $\begin{array}{l}\text { "Atendimento } \\
\text { Educacional } \\
\text { Especializado de } \\
\text { Alunos com } \\
\text { Altas } \\
\text { Habilidades/Sup } \\
\text { erdotação na } \\
\text { cidade de } \\
\text { Londrina, } \\
\text { Paraná" }\end{array}$ & Dissertação & $\begin{array}{l}\text { O objetivo do } \\
\text { trabalho foi } \\
\text { examinar como } \\
\text { é desenvolvido } \\
\text { o trabalho na } \\
\text { Sala de Recurso } \\
\text { destinada a } \\
\text { AH/SD } \\
\text { Região } \\
\text { Metropolitana } \\
\text { de Londrina/PR }\end{array}$ & 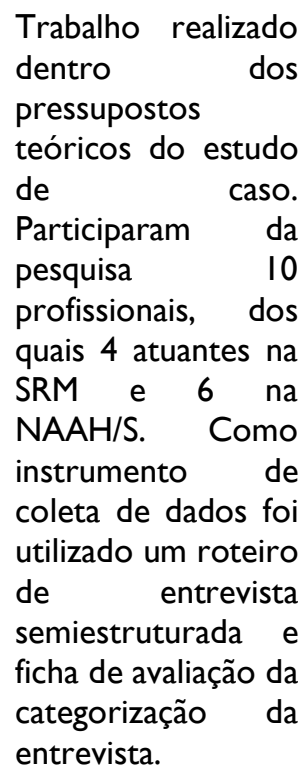 \\
\hline $\begin{array}{l}2014 \\
\text { Canoas/ } \\
\text { RS }\end{array}$ & $\begin{array}{l}\text { KLAGENBERG, } \\
\text { Rosalina Moro }\end{array}$ & 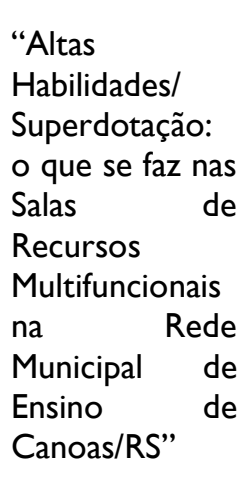 & Dissertação & $\begin{array}{l}\text { O estudo teve } \\
\text { como finalidade } \\
\text { averiguar o } \\
\text { funcionamento } \\
\text { das Salas de } \\
\text { Recursos } \\
\text { Multifuncionais } \\
\text { municipais da } \\
\text { cidade de } \\
\text { Canoas/RS, da } \\
\text { diante } \\
\text { temática da }\end{array}$ & $\begin{array}{l}\text { utilizando-se dos } \\
\text { modelos qualitativo } \\
\text { e quantitativo, a } \\
\text { pesquisa contou } \\
\text { com a participação } \\
\text { de } 32 \text { profissionais } \\
\text { atuantes na sala de } \\
\text { recursos } \\
\text { multifuncionais e } 2 \\
\text { gestores da } \\
\text { secretaria de } \\
\text { educação }\end{array}$ \\
\hline
\end{tabular}

Olhar de professor, Ponta Grossa, v. 24, p. I-22, e-18288.086, 2021.

Disponível em <https://revistas2.uepg.br/index.php/olhardeprofessor> 


\begin{tabular}{|c|c|c|c|c|c|}
\hline & & & & $\mathrm{AH} / \mathrm{SD}$ & $\begin{array}{l}\text { município, } \\
\text { responsáveis por } \\
\text { gerir a SRM, dessa } \\
\text { forma responderam } \\
\text { questionários r a } \\
\text { respeito de sua } \\
\text { formação } \\
\text { profissional, } \\
\text { conhecimento } \\
\text { bibliográfico r a } \\
\text { respeito da AH/SD } \\
\text { e participaram de } \\
\text { uma oficina a } \\
\text { respeito } \\
\text { temática, seguido de } \\
\text { um formulário de } \\
\text { autoavaliação. }\end{array}$ \\
\hline $\begin{array}{l}2014 \\
\text { Porto Alegre/ } \\
\text { RS }\end{array}$ & $\begin{array}{l}\text { DREYER, } \\
\text { Jessica }\end{array}$ & $\begin{array}{l}\text { "Infância } \\
\text { Superdotada: } \\
\text { um olhar sobre } \\
\text { a constituição } \\
\text { de si, das } \\
\text { crianças } \\
\text { participantes de } \\
\text { um grupo de } \\
\text { altas } \\
\text { habilidades" }\end{array}$ & Dissertação & $\begin{array}{l}\text { O trabalho se } \\
\text { propõe a } \\
\text { analisar como } \\
\text { se } \\
\text { compreendem } \\
\text { as crianças do } \\
\text { primeiro ao } \\
\text { quinto ano do } \\
\text { ensino } \\
\text { fundamental I, } \\
\text { participantes } \\
\text { que recebem } \\
\text { atendimento } \\
\text { especializado } \\
\text { no grupo para } \\
\text { AH/SD. }\end{array}$ & $\begin{array}{lr}\text { A pesquisa } & \text { foi } \\
\text { desenvolvida } & \text { se } \\
\text { baseando } & \text { no } \\
\text { modelo } & \text { de } \\
\text { pesquisa- } & \\
\text { intervenção, } & \text { de } \\
\text { modo a contar } & \text { com } \\
\text { a participação } & \text { de } \\
\text { professores } & \text { e } \\
\text { alunos participantes } \\
\text { do grupo de } \\
\text { atendimento r de } \\
\text { especializado de } \\
\text { alunos com AH/SD. }\end{array}$ \\
\hline $\begin{array}{l}2017 \\
\text { Manaus/ } \\
\text { AM }\end{array}$ & $\begin{array}{l}\text { OLIVEIRA, } \\
\text { Débora da } \\
\text { Cunha Nogueira }\end{array}$ & \begin{tabular}{|ll} 
“O Núcleo de \\
Atividades de \\
Altas \\
Habilidades/ & \\
Superdotação & \\
da cidade de & \\
Manaus & \\
(NAAH/S): & \\
Desafios & e \\
perspectiva”" &
\end{tabular} & Dissertação & \begin{tabular}{lr}
\multicolumn{2}{l}{ O trabalho tem } \\
\multicolumn{2}{|l}{ como objetivo } \\
observar & as \\
relações & \\
humanas & \\
existentes & no \\
NAAH/S r de \\
Manaus, bem \\
como o reu \\
reflexo rr para \\
com r os \\
indivíduos \\
envolvidos.
\end{tabular} & 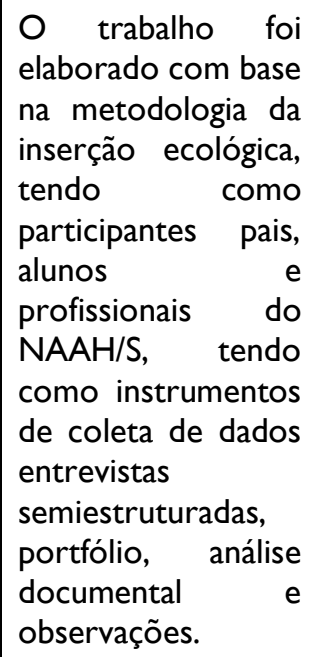 \\
\hline $\begin{array}{l}2020 \\
\text { Cascavel/ } \\
\text { PR }\end{array}$ & $\begin{array}{l}\text { VIEIRA, Sandra } \\
\text { Maciel }\end{array}$ & $\begin{array}{l}\text { “O Atendimento } \\
\text { Educacional } \\
\text { Especializado } \\
\text { para Altas }\end{array}$ & Dissertação & $\begin{array}{l}\text { A pesquisa tem } \\
\text { como objetivo } \\
\text { verificar se as } \\
\text { políticas } \\
\text { públicas }\end{array}$ & $\begin{array}{lrr}\text { A } & \text { pesquisa } & \text { foi } \\
\text { elaborada } & \text { com } & \text { base } \\
\text { no } & \text { percurso } \\
\text { metodológico } & \text { da }\end{array}$ \\
\hline
\end{tabular}

Olhar de professor, Ponta Grossa, v. 24, p. I-22, e-18288.086, 2021.

Disponível em <https://revistas2.uepg.br/index.php/olhardeprofessor> 


\begin{tabular}{|c|c|c|c|c|}
\hline & & $\begin{array}{l}\text { Habilidades/ } \\
\text { Superdotação na } \\
\text { reder pública } \\
\text { estadual do NRE } \\
\text { de Cascavel - PR: } \\
\text { das políticas às } \\
\text { práticas" }\end{array}$ & $\begin{array}{l}\text { estão efetivando } \\
\text { o direito da AEE } \\
\text { aos alunos com } \\
\text { AH/SD. }\end{array}$ & $\begin{array}{l}\text { pesquisa de campo, } \\
\text { de forma a } \\
\text { participarem diretor } \\
\text { e professores da } \\
\text { primeira SRM do } \\
\text { NRE e diretores, } \\
\text { professores, pais e } \\
\text { alunos das atuais } \\
\text { salas. }\end{array}$ \\
\hline
\end{tabular}

Fonte: Elaborado pelas autoras com base nas dissertações pesquisadas na BDTD, 2020.

Conforme pode ser observado no quadro I, não foram encontradas teses sobre a nossa temática na busca realizada, de forma que as seis produções que compuseram o corpus de nossa análise são dissertações de mestrado. Todos os estudos são qualitativos e envolveram pesquisa de campo.

A seguir apresentamos primeiramente uma análise quantitativa das produções selecionadas. Na sequência, apresentamos, também, uma análise qualitativa dessas produções.

\section{Análise quantitativa das produções}

Para a realização da referida análise foram elencados três quesitos para verificação, sendo eles: I) A região do país em que a pesquisa foi realizada; 2) $\bigcirc$ tipo de produção acadêmica (tese ou dissertação); 3) O tipo de instituição na qual a pesquisa foi desenvolvida (pública ou privada).

Dessa forma, o quadro 2 apresenta a distribuição da pesquisa por regiões brasileiras, por esfera administrativa/instituição e programa de pós-graduação.

Quadro 2: Distribuição da pesquisa por regiões brasileiras, por esfera administrativa/instituição e programa de pós-graduação.

\begin{tabular}{|c|c|c|c|c|c|c|c|}
\hline \multirow{2}{*}{$\begin{array}{c}\text { Regiões } \\
\text { brasileiras }\end{array}$} & \multicolumn{2}{|c|}{$\begin{array}{c}\text { Tese (T) } \\
\text { Dissertações (D) }\end{array}$} & \multirow{2}{*}{$\begin{array}{c}\text { TOTAL } \\
\text { T/D }\end{array}$} & \multicolumn{3}{|c|}{ Esferas administrativas } & \multirow{2}{*}{ TOTAL } \\
\hline & $\mathbf{T}$ & D & & $\begin{array}{l}\text { Públicas } \\
\text { Federais }\end{array}$ & $\begin{array}{l}\text { Públicas } \\
\text { Estaduais }\end{array}$ & Privada & \\
\hline Norte & - & I & I & I & - & - & I \\
\hline Nordeste & - & - & - & - & - & - & \\
\hline Centro-Oeste & - & - & - & - & - & - & \\
\hline Sudeste & - & - & - & - & - & - & \\
\hline Sul & - & 5 & 5 & 2 & 2 & I & 5 \\
\hline TOTAL & 0 & 6 & 6 & 3 & 2 & I & 6 \\
\hline
\end{tabular}

Fonte: Elaborado pelas autoras, com base nas dissertações pesquisadas na BDTD, 2020. 
Como pode ser observado no quadro 2, não foram encontradas teses sobre a temática $A H / S D$ e AEE. Portanto, foram analisadas seis (6) dissertações defendidas no período entre $20 \mathrm{II}$ e 2020.

De um total de seis dissertações, quatro pertencem a Programas de Pós-Graduação em Educação, uma a um Programa de Pós-Graduação em Antropologia Social e uma a um Programa de Pós-Graduação em Psicologia.

A respeito da distribuição das produções selecionadas dentro do território brasileiro, nota-se que a região sul lidera a produção com cinco trabalhos, sendo três produzidas no estado do Rio Grande do Sul e duas no estado do Paraná. Foi encontrado um trabalho produzido na região norte, no estado do Amazonas.

Nota-se, ainda, a partir do quadro 2, que das seis produções analisadas, cinco $(83,33 \%)$ foram produzidas dentro de Programas de Pós-Graduação vinculados a universidades públicas e apenas uma (16,67\%) foi produzida em uma universidade privada. Esses dados estão em consonância com Escobar (2019) ao apresentar dados divulgados pela base Web of Science que aponta que atualmente $90 \%$ das produções acadêmicas brasileiras são elaboradas em instituições públicas.

No que se refere ao número de produções publicadas no período de busca, como pode ser observado no quadro 3 , foram encontradas uma produção no ano de $20 \mathrm{II}$, uma no ano de 2013 , duas no ano de 2014, uma no ano de 2017 , e uma no ano de 2020 , não sendo encontrada nenhuma nos demais anos pesquisados.

Quadro 3: Pesquisas sobre o AEE para alunos com AH/SD no período entre $201 \mathrm{I}$ a 2020.

\begin{tabular}{|c|c|c|c|}
\hline Ano & Teses & Dissertações & Total \\
\hline 2011 & - & 1 & 1 \\
\hline 2012 & - & - & - \\
\hline 2013 & - & 1 & 1 \\
\hline 2014 & - & 2 & 2 \\
\hline 2015 & - & - & - \\
\hline 2016 & - & - & - \\
\hline 2017 & - & 1 & - \\
\hline 2018 & - & - & - \\
\hline 2019 & - & - & 1 \\
\hline 2020 & - & 1 & 6 \\
\hline TOTAL & 0 & 6 & 2020 \\
\hline
\end{tabular}

Fonte: Elaborado pelas autoras, com base nas dissertações pesquisadas na BDTD, 2020. 
Por fim, a respeito do referencial teórico abordado em cada uma das pesquisas realizadas, percebe-se, conforme o quadro 4, que três se utilizaram dos estudos de Renzulli (2004) acerca da teoria dos três anéis, sendo que em duas delas também foram utilizados os estudos de Gardner (1994; 2000). Há, ainda, uma que se utiliza dos Documentos Legais para conceituar esse alunado, uma que se baseia também nos escritos de Andrés (2010), Pérez (2006) e Delou (2007), bem como de Rifiotis (2007), e uma que se baseia nos estudos da teoria Histórico-cultural de Vigotski.

Quadro 4: Referencial teórico utilizado nas pesquisas sobre o AEE para alunos com AH/SD.

\begin{tabular}{|c|c|}
\hline Título & Referencial Teórico \\
\hline $\begin{array}{l}\text { "Entre uma sala e outra: uma experiência } \\
\text { etnográfica a partir das salas de recursos para altas } \\
\text { habilidades/ } \\
\text { Superdotação em Porto Alegre, Rio Grande do Sul" }\end{array}$ & $\begin{array}{l}\text { O trabalho se utiliza de escritos de Andrés (2010), } \\
\text { Pérez (2006) e Delou (2006) para tratar da AH/SD, além } \\
\text { dos escritos de Rifiotis (2007) ao se referir a emergência } \\
\text { deste público em ser reconhecido como detentor de } \\
\text { direitos. }\end{array}$ \\
\hline $\begin{array}{l}\text { "Atendimento Educacional Especializado de Alunos } \\
\text { com Altas Habilidades/Superdotação na cidade de } \\
\text { Londrina, Paraná" }\end{array}$ & $\begin{array}{l}\text { Trabalho realizado com base em Renzulli (2004; 20II; } \\
\text { 20I2) e Gardner (I994; 2000). }\end{array}$ \\
\hline $\begin{array}{l}\text { "Altas Habilidades/ Superdotação: o que se faz nas } \\
\text { Salas de Recursos Multifuncionais na Rede Municipal } \\
\text { de Ensino de Canoas/RS" }\end{array}$ & $\begin{array}{l}\text { O estudo foi realizado a partir da teoria dos Três Anéis } \\
\text { de Renzulli (2004), além de Gardner (20I2) sobre as } \\
\text { inteligências múltiplas. }\end{array}$ \\
\hline $\begin{array}{l}\text { "Infância Superdotada: um olhar sobre a } \\
\text { constituição de si, das crianças participantes de um } \\
\text { grupo de altas habilidades" }\end{array}$ & $\begin{array}{l}\text { Ao discorrer a respeito da } \mathrm{AH} / \mathrm{SD} \text { o trabalho se baseia } \\
\text { nos documentos legais do Ministério da Educação e } \\
\text { Cultura (MEC). }\end{array}$ \\
\hline $\begin{array}{l}\text { "O Núcleo de Atividades de Altas Habilidades/ } \\
\text { Superdotação da cidade de Manaus (NAAH/S): } \\
\text { Desafios e perspectiva" }\end{array}$ & $\begin{array}{l}\text { A pesquisa se pauta na teoria dos Três Anéis de Renzulli } \\
(1986,2004) \text {. }\end{array}$ \\
\hline $\begin{array}{l}\text { "O Atendimento Educacional Especializado para } \\
\text { Altas Habilidades/ } \\
\text { Superdotação na rede pública estadual do NRE de } \\
\text { Cascavel - PR: das políticas às práticas" }\end{array}$ & $\begin{array}{l}\text { A pesquisa se baseia nos estudos da Teoria Histórico- } \\
\text { Cultural. }\end{array}$ \\
\hline
\end{tabular}

Fonte: Elaborado pelas autoras, com base nas dissertações pesquisadas nas BDTD, 2020.

Os dados revelam, portanto, que há uma predominância do referencial proposto por Renzulli (2004). 


\section{Análise qualitativa das produções}

O primeiro estudo encontrado, de autoria de Fernandes (20lI), denomina-se "Entre uma sala e outra: uma experiência etnográfica a partir das salas de recursos para altas habilidades/Superdotação em Porto Alegre, Rio Grande do Sul”. O estudo teve como objetivo apresentar a emergência do alunado com AH/SD como integrante do público da Educação Especial. À vista disso se utilizou de entrevista e roteiro de observação como instrumentos de coleta de dados, tendo como participantes professores, pais e alunos de 8 salas de AEE, do município de Porto Alegre/RS, sendo uma municipal e sete estaduais.

Por se tratar de uma pesquisa da área de Antropologia Social, a autora se dedicou a expor de forma detalhada questões referentes à localização, estrutura física e material das salas participantes, pontuando o contraste entre elas, uma vez que algumas apresentavam estrutura satisfatória e outras não, além de caracterizar a professora atuante e contextualizar as oficinas ofertadas em cada instituição.

De acordo com os resultados da pesquisa, todas as salas em funcionamento tiveram sua fundação a partir de um curso ofertado para professoras pela Secretaria de Educação com a Universidade Federal do Rio Grande do Sul (UFRGS). Sobre a atuação destas profissionais, a autora destacou que além da mediação pedagógica dos estudantes, eram responsáveis pela oferta de formação dentro do município.

Ainda no que tange aos resultados, Fernandes (201 I) constatou que o ingresso dos alunos nessas salas decorria de variadas formas, dentre elas: indicação dos professores das salas de aulas regulares, indicação das famílias, de colegas, além da autoindicação, para então passarem por um processo de identificação, sendo as professoras encarregadas por apresentarem os pareceres. De acordo com a autora, as professoras, em seus relatos, reconheciam a necessidade de aprimorar seus parâmetros de avaliação, a fim de que esses alunos tivessem acesso aos seus direitos.

A autora concluiu que a questão de identificação e atendimento especializado para sujeitos com $A H / S D$, conforme previsto em legislação, para essas salas, vão além da visibilidade e direito a atendimentos às suas especificidades, pois envolve também a necessidade de evitar a evasão escolar de muitos alunos.

O segundo estudo encontrado em nossa revisão, de autoria de Lyra (2013), intitula-se "Atendimento Educacional Especializados de Alunos com Altas Habilidades/Superdotação na cidade de Londrina, Paraná". O estudo teve como objetivo examinar como é desenvolvido o trabalho na Sala de Recurso destinada a alunos com AH/SD na Região Metropolitana de Londrina/PR.

Participaram da pesquisa dez profissionais, dos quais quatro atuavam na SRM e seis no NAAH/S. A coleta de dados foi feita por meio de entrevista semiestruturada e ficha de avaliação da categorização 
da entrevista, tendo o tratamento das informações sido realizado por meio de análise e tabulação das entrevistas.

Como resultados, Lyra (2013) verificou que todos os profissionais entrevistados possuíam grau de especialização em Educação Especial, sendo a maioria com formação em Pedagogia. A autora constatou, ainda, que esses profissionais possuíam entendimento multidimensional acerca das características do educando com AH/SD, mostrando preocupação com a oferta do AEE. A respeito do ingresso neste atendimento, pontuou a possibilidade de várias formas, tais como encaminhamento pela escola, família, colegas ou psicólogos, para então dar início ao processo de identificação, o qual era realizado, por formulários, entrevistas, observação ou testes psicométricos. A autora ressaltou a falta de conhecimento a respeito dos alunos com AH/SD por parte das professoras da sala de aula regular e, o que acaba por prejudicar o encaminhamento dos alunos.

Referente ainda aos profissionais, Lyra (2013) constatou que esses se sentiam satisfeitos com o seu trabalho no AEE, mas que percebiam a necessidade de realizar mais cursos de formação. No que se refere às adversidades que cercam o trabalho, os participantes da pesquisa ressaltaram a falta de recursos materiais, o que contribui para uma limitação quanto às possibilidades do atendimento. Além disso, revelaram o anseio para que ocorressem parcerias com organizações que pudessem auxiliar neste atendimento, tais como: universidades e instituições públicas e privadas.

Sobre os NAAH/S, Lyra (20/3) concluiu que a divulgação da temática da AH/SD, se mostra extremamente necessária para efetivação do AEE, uma vez que essa falta de informação interfere diretamente na não identificação desse alunado. Sobre as parcerias, considerou ser de grande importância para auxílio financeiro, tanto para o núcleo, no desenvolvimento do atendimento, quanto para os discentes atendidos, na assistência ao acesso a estes ambientes. Quanto ao trabalho desenvolvido, expôs que o bom funcionamento atual do NAAH/S, está totalmente ligado ao empenho dos profissionais em atuação, sendo eles responsáveis pelo auxílio para a permanência dos alunos financeiramente mais necessitados.

Diante do averiguado, a autora sugere a necessidade da integração entre os núcleos de atendimento aos discentes com AH/SD em funcionamento no território nacional, como uma maneira a propiciar diálogo e troca de experiência entre os profissionais que lá trabalham.

Com ○ título "Altas Habilidades/Superdotação: o que se faz nas Salas de Recursos Multifuncionais na Rede Municipal de Ensino de Canoas/RS”, de Klagenberg (2014), o terceiro estudo integrante de nossa revisão teve como objetivo investigar o tratamento da temática da AH/SD pelos professores da SRM do município de Canoas/RS. Participaram do estudo trinta e dois professores das SRM e dois gestores da Secretaria de Educação. Para a coleta de dados foi utilizada a entrevista 
semiestruturada e autoavaliação dos participantes em oficina ofertada pela pesquisadora sobre a temática, a pedido desses profissionais.

Os resultados da pesquisa revelaram que os profissionais em atuação, participantes do estudo, apresentavam formação insuficiente quanto às especificidades do $\mathrm{AEE}$, mesmo a maioria tendo realizado algum curso de especialização na área da educação. No que se refere às salas em funcionamento no município, a autora constatou que nenhuma era dedicada especificamente ao atendimento de alunos com AH/SD. A autora constatou, ainda, que as políticas públicas de encaminhamento de recursos materiais não estavam sendo completamente efetivadas, uma vez que, na maioria dos casos, os kits enviados pelo governo estavam incompletos.

No que diz respeito às concepções dos participantes da pesquisa sobre a AH/SD, Klagenberg (2014) verificou que alguns destes profissionais mencionaram diferentes autores para caracterizar os alunos. Todavia ainda foram encontradas, ainda, definições arcaicas e inadequadas, refletindo no trabalho de identificação, encaminhamento e enriquecimento curricular. Isso revela a urgência dos gestores da educação do município em qualificá-los para o exercício da profissão.

Klagenberg (2014) constatou, ainda, que os participantes da pesquisa se mostraram conscientes sobre a importância de aprofundar sua formação a respeito das especificidades da temática das AH/SD.

Outro aspecto abordado por Klagenberg (20l4), é que o atendimento dos alunos com AH/SD se apresentava praticamente oculto no contexto pesquisado, tendo em vista que apenas um aluno recebia atendimento. Para a autora, isso revela uma lacuna na formação específica dos profissionais quanto ao AEE, ressaltando a falta de profissionais capacitados e a alta rotatividade de profissionais para essa função.

O quarto estudo, elaborado por Dreyer (20I4), intitulado "Infância Superdotada: um olhar sobre a constituição de si, das crianças participantes de um grupo de altas habilidades", teve como objetivo analisar como se compreendem as crianças do primeiro ao quinto ano do ensino fundamental I, participantes que recebem o atendimento especializado no grupo para AH/SD.

Como metodologia se fundamentou nos moldes da pesquisa-intervenção, tendo como participantes professores e quatro alunos com AH/SD do grupo para atendimento especializado do município de Porto Alegre/RS. A investigação foi organizada a partir da elaboração de um roteiro com seis encontros, para interação com os integrantes do grupo, entretanto os caminhos da pesquisa foram se adequando conforme sua necessidade.

Os resultados da pesquisa apontaram uma variedade de formas de ingresso dos alunos ao grupo, verificando que nem todos haviam passado por um processo detalhado de identificação. Sobre o tratamento da temática pelos professores, Dreyer (2014) destacou a forma velada como era tratada no grupo, tendo como embasamento a justificativa de evitar a prepotência dos participantes diante 
outros colegas, todavia em contradição a essa crença averiguou-se que os alunos atendidos tinham uma boa interação com os demais colegas, pois evitavam expor suas vivências cotidianas neste ambiente como forma de proteger seu espaço exclusivo, uma vez que desmontaram gostar de fazer parte do grupo de atendimento especializado. Para a autora, diferente da sala de aula regular, na qual esses alunos são apenas sujeitos passivos diante do que ocorre, no grupo de AH/SD eles são ativos tendo a possibilidade de fazer parte da organização cotidiana, com a sugestão de atividades e a direção que essa toma.

Dreyer (2014) concluiu que mais do que definir as crianças com AH/SD, segundo um padrão, é necessário enxergá-las como sujeitos únicos, com experiências próprias, sendo imprescindível o movimento de escutá-las para se definir as possibilidades de trabalho.

O quinto estudo de nossa revisão, de autoria de Oliveira (2017), intitula-se "O Núcleo de Atividades de Altas Habilidades/Superdotação da cidade de Manaus (NAAH/S): desafios e perspectivas". O estudo teve como finalidade observar as relações humanas existentes no NAAH/S, situado em uma escola pública de Manaus, bem como o seu reflexo para com os indivíduos envolvidos.

Participaram do estudo dezenove sujeitos, sendo cinco pais, cinco alunos e nove profissionais do NAAH/S, dentre eles a coordenadora, cinco professores e três psicólogas. Como metodologia, a pesquisa adotou a inserção ecológica, de forma a se utilizar de entrevistas semiestruturadas, portfólio desenvolvido com os alunos, análise documental sobre o histórico e funcionamento do núcleo e observações da pesquisadora acerca da rotina do atendimento.

No que se refere aos resultados, Oliveira (2017) destacou que após o processo de identificação do discente, este passa a ser acompanhado quanto às suas facilidades e dificuldades. A partir da inserção deste aluno no $\mathrm{NAAH} / \mathrm{S}$, os pais relataram que as relações familiares se tornaram mais saudáveis, pois passaram a amparar seus filhos, uma vez que até então o sentimento de insegurança os acompanhavam.

Ainda sobre a percepção da família a respeito da temática, a Oliveira (2017) demarcou o descontentamento dos pais quanto ao despreparo das escolas para lidar com as AH/SD dos filhos. No que tange aos profissionais, a autora ressaltou que mesmo em meio às dificuldades estruturais e materiais, esses desempenhavam um trabalho com muito comprometimento, de maneira a visar o desenvolvimento de cada sujeito, mesmo não tendo formação específica para o trabalho com alunos com AH/SD. A respeito dos próprios alunos, Oliveira (2017) assinalou que estes reconheciam a importância do NAAH/S para o seu desenvolvimento, assentindo a influência em questões referente à escola, socialização e família.

Os resultados da pesquisa revelaram, ainda, a falta de recursos advindos da Secretaria de Educação destinados ao custeio do núcleo, interferindo diretamente no atendimento prestado aos

Olhar de professor, Ponta Grossa, v. 24, p. I-22, e-18288.086, 202 I.

Disponível em <https://revistas2.uepg.br/index.php/olhardeprofessor> 
alunos. Para a autora, o NAAH/S possui um papel fundamental no atendimento dos alunos e pais e na formação profissional, mas seria melhor se contasse com o apoio de outras instâncias educacionais

Oliveira (2017) concluiu que o trabalho desenvolvido em conjunto entre os sujeitos envolvidos no núcleo, foi de extrema valia no apoio educacional e psicológico dos pais e alunos que até então se encontravam perdidos em relação à forma como lidar com as $\mathrm{AH} / \mathrm{SD}$, de forma que o trabalho dos professores se mostrou essencial nesse processo. Sobre os recursos infraestruturais e profissionais, a autora demarcou a importância da instituição de políticas públicas que visem a formação e melhoria das condições materiais e de trabalho, embora o funcionamento do núcleo tenha conseguido enfrentar tais adversidades.

Por fim, a sexta e última pesquisa encontrada em nossa revisão, intitulada "O Atendimento Educacional Especializado para Altas Habilidades/Superdotação na rede pública estadual do NRE de Cascavel - PR: das políticas às práticas", de autoria de Vieira (2020), teve como objetivo verificar se as políticas públicas estão efetivando o direito da AEE aos alunos com AH/SD.

Participaram do estudo o diretor e um ex-aluno da primeira SRM do NRE, seis professores, divididos entre os da primeira sala e os atualmente em atuação, cinco diretores, dez pais e quatorze alunos das atuais salas.

Os instrumentos de coleta de dados foram: questionários, respondidos pelos pais, alunos e profissionais em atuação, entrevistas realizadas com os sujeitos envolvidos com a primeira SRM e observação dos professores e alunos durante o atendimento.

Os resultados da pesquisa revelaram falhas quanto à identificação do aluno com AH/SD que, segundo indicado pelas professoras, se davam principalmente pela falta de formação dos profissionais em atuação nas salas regulares. Ressaltaram, também, que excetuando um município jurisdicionado, a responsabilidade da realização deste processo é das escolas pertencentes àquele NRE, ocasionando a identificação tardia. Por outro lado, demarcaram um crescimento no número de alunos indicados ao atendimento, fato relacionado pela autora com a aproximação do NRE com o ensino superior em ofertas de cursos de formação.

Acerca dos recursos materiais e didáticos pedagógicos para $\circ$ trabalho com alunos com $\mathrm{AH} / \mathrm{SD}$, os resultados apontaram para uma precariedade. Assim, mesmo estando amparados por questões legais, observa-se o não cumprimento dessas políticas públicas, questão esta que acompanha o atendimento desde a sua fundação, sendo uma das justificativas para o fechamento das duas primeiras salas no NRE.

Sobre os profissionais, Vieira (2020) apontou que para atuação docente era necessária a formação em Educação Especial, porém não necessitava especificamente ser na área da AH/SD, pois esses profissionais mencionaram a preocupação com planejamento e preparo de materiais que 
suprissem a necessidade de cada aluno. A autora constatou, ainda, que uma dificuldade encontrada foi a rotatividade de professores, a qual era motivada pela forma de organização do trabalho nas SRM pela Secretaria de Educação e pela falha na oferta de formação continuada.

No que concerne aos alunos e suas famílias, a pesquisadora constatou que os pais se mostraram participativos, cientes das dificuldades e facilidades de seus filhos, de modo que a maioria não apontou nenhum empecilho para a participação do atendimento, já referente aos alunos destacou que estes são capazes de indicar a importância do AEE em seu desenvolvimento, fato esse também levantado pelo ex-aluno entrevistado que defendeu a ampliação deste atendimento. Destacou, também, a percepção desses discentes de que este ambiente lhes conferiu noção de pertencimento a um grupo, deixando de se sentirem como diferentes.

A autora concluiu que as dificuldades listadas pelos participantes, acompanham esse atendimento desde sua implantação no NRE, de forma que não se trata de desafios apenas dessa realidade, mas sim de todo o contexto da educação. Frente a isso destacou a importância da identificação precoce como forma de estímulo à prática das políticas públicas.

Vieira (2020), com base em Ribeiro (2017), defendeu que as políticas públicas federais destinadas ao atendimento às pessoas com AH/SD, não atendem todo o território da mesma maneira. Com isso, a responsabilidade de um atendimento de qualidade recai sobre outras instâncias, tais como: ensino superior e secretarias de educação, de forma que somente a existência de questões legais não basta, há a necessidade de se estabelecer estratégias para que essas possam ser efetivadas.

Mesmo partindo da temática do AEE prestado aos alunos com AH/SD, cada uma das pesquisas aqui elencada, se dedica a retratar a realidade encontrada de forma a evidenciar suas particularidades. Entretanto, entre elas há algumas questões que as aproximam, de modo a apontar em sua maioria que as condições encontradas neste atendimento não correspondem ao que prevê os aspectos legais que asseguram e balizam esse atendimento. De um modo geral, faltam recursos, o que compromete as condições de trabalho (FERNANDES, 20II; LYRA, 20I3; KLAGENBERG, 20I4; OLIVEIRA, 20I7; VIEIRA, 2020). Além disso, a formação dos profissionais atuantes neste atendimento é deficitária (KLAGENBERG, 20I4; OLIVEIRA, 20I7; VIEIRA, 2020).

Por sua vez, Lyra (2013) e Oliveira (2017) ressaltam o empenho dos profissionais para desenvolver seus trabalhos, mesmo diante das adversidades que cercam os atendimentos das realidades analisadas.

Outro ponto comum entre as publicações analisadas, diz respeito às questões particulares referentes à realidade dos alunos frente a este atendimento, bem como a influência positiva que o atendimento realizado exerce na família e na escola, pois promove a integração entre essas duas instâncias, conforme abordado por Fernandes (20II), Oliveira (2017) e Vieira (2020). 


\section{Considerações Finais}

A presente pesquisa teve como objetivo verificar o estado do conhecimento acerca do atendimento educacional especializado ofertado para os alunos com AH/SD, por meio de teses e dissertações produzidas no Brasil.

Nesse sentido, buscamos as publicações na Biblioteca Digital Brasileira de Teses e Dissertações do Instituto Brasileiro de Informação em Ciência e Tecnologia (BDTD/IBICT), de forma que atendessem nossos requisitos, adotando como recorte temporal o período de $20 \mathrm{II}$ a 2020.

Diante dos resultados encontrados nas pesquisas elencadas, verificamos que os alunos com $\mathrm{AH} / \mathrm{SD}$ embora integrem o público alvo da educação especial e, dessa forma, detenham o direito de receber um atendimento especializado, ainda hoje não têm recebido um atendimento condizente com suas necessidades, conforme postulado por Corrêa e Delou (2016).

Dessa forma, as publicações de nossa revisão apresentam como alguns desses desafios, a identificação desses discentes, sobre essa questão, Guimarães e Ourofino (2007), apontam que esse processo deve dispor de diversas fontes de dados, que retratam globalmente o sujeito, não se restringindo a medição de sua inteligência por meio de testes psicométricos, sendo a família, professores, colegas e o próprio estudante, fonte de informação. Além disso, as produções ressaltam a importância do conhecimento da família e comunidade escolar a respeito da temática.

Destacam, também, o não cumprimento das políticas públicas e a falta de condições materiais e físicas, fator diretamente relacionado com a qualidade do atendimento. Dessa forma, reiteramos a importância de articulação de mecanismos que garantam o funcionamento das questões legais que balizam o AEE.

Outro aspecto mencionado como de grande importância para a efetivação deste atendimento é a formação dos profissionais da educação, uma vez que os professores em atuação direta com esse alunado, como no caso do AEE, necessitam de devida formação na área que trabalhem com a estimulação de seus potenciais, segundo apontam Bahiense e Rossetti (2014). Além de professores das salas de aulas regulares devidamente qualificados que consigam reconhecer as características desses discentes para que possam ser encaminhados para o processo de identificação.

Esse apontamento está em conformidade com Bahiense e Rossetti (2014), ao afirmarem a importância dessa qualificação profissional, uma vez que por estarem cotidianamente com os alunos, os professores conseguem fazer uma primeira identificação, com base nos indicadores por eles apresentados. Nesse âmbito as publicações, reiteram que a educação superior deve englobar a referida temática desde a formação inicial. Mas destacam, também, a necessidade de oferta da formação continuada por parte dos gestores da educação. 
Salientamos que a pesquisa foi de grande importância, por nos proporcionar reflexões acerca da formação de professores e as fragilidades envolvendo as questões políticas, infraestruturais e educativas que cercam o alunado do AEE, de forma a contribuir em nossa formação.

Diante disso, reiteramos que a pesquisa não esgota a temática. Sendo assim, salientamos a relevância de trabalhos nessa área, uma vez que estudos voltados a esses educandos ainda são escassos, e se trata de uma temática de importância não apenas acadêmica, mas também social.

\section{Referências}

ALENCAR, E. M. L. S.; FLEITH, D. S. A atenção ao aluno que se destaca por um Potencial Superior. Revista do Centro de Educação, Santa Maria, n. 27, p. I-5, 2005. Disponível em: <https://periodicos.ufsm.br/educacaoespecial/article/view/4346/2565>. Acesso em: 2 I fev. 202I.

ANDRÉS, Aparecida. Educação de Alunos Superdotados/Altas Habilidades-Legislação e Normas Nacionais - Legislação e Normas Internacionais. Biblioteca Digital da Câmara dos Deputados. 2010. Disponível em: file:///C:/Users/solan/Downloads/educacao_alunos_aparecida\%20(I).pdf. Acesso em: 2 I fev, 202I.

ANTIPOFF, C. A.; CAMPOS, R. H. F. Superdotação e seus mitos. Revista Semestral da Associação Brasileira de Psicologia Escolar e Educacional, São Paulo, v. 14, ed. 2, p. 301-309, 2010. Disponível em: <https://www.scielo.br/pdf/pee/vl4n2/a |2v|4n2.pdf>. Acesso em: 12 fev. 2021 .

BAHIENSE, T. R. S.; ROSSETTI, C. B. Altas Habilidades/Superdotação no Contexto Escolar: Percepções de Professores e Prática Docente. Revista Brasileira de Educação Especial, Marília, v. 20, n. 2, p. 195-208, 20I4. Disponível em: https://www.scielo.br/pdf/rbee/v20n2/04.pdf. Acesso em: 10 maio 2021.

BRASIL. MEC/SEESP. Decreto $\mathbf{n}^{\circ} \mathbf{7 . 6}$ I I, de 17 de novembro de 20I I. Dispõe sobre a educação especial, o atendimento educacional especializado e dá outras providências. Brasília: $201 \mathrm{I}$.

BRASIL. MEC/SEESP. Documento Orientador: Execução da Ação. Brasília: 2006. Disponível em: <http://portal.mec.gov.br/seesp/arquivos/doc/documento\%20orientador_naahs_29_05_06.doc.>. Acesso em: 21 fev. 2021.

BRASIL. Lei $\mathbf{n}^{\circ}$ 9394, de 20 de dezembro de 1996. Estabelece as diretrizes e bases da educação nacional. Brasília: 1996. Disponível em: http://www.planalto.gov.br/ccivil_03/LEIS/L9394.htm Acesso em: 21 fev. 2021 .

BRASIL. CNE. CEB. Resolução $\mathbf{n}^{\circ}$ 4, de 2 de outubro de 2009, que institui diretrizes operacionais para o atendimento educacional especializado na educação básica, modalidade educação especial. Brasília: 2009. Disponível em: http://portal.mec.gov.br/dmdocuments/rceb004_09.pdf. Acesso em: 21 fev. 2021 .

CORRÊA, Rosa Maria; DELOU, Cristina Maria Carvalho. Atendimento educacional especializado para alunos com altas habilidades ou superdotação: possibilidades e alternativas. In: GOMES, Robéria Vieira Barreto; FIGUEIREDO, Rita Vieira de; SILVEIRA, Selene Maria Penaforte, FACCIOLI, Ana Maria. (orgs.). Políticas de inclusão escolar e estratégias pedagógicas no atendimento educacional especializado. Fortaleza: UFCE; Brasília: MC\&C, 2016. p. 155-163. 
Delou, Cristina M. C. (2007). Educação do Aluno com Altas Habilidades/Superdotação: Legislação e Políticas Educacionais para a Inclusão. In: FLEITH, Denise de Souza (Org.). A Construção de Práticas Educacionais para Alunos com Altas Habilidades / Superdotação. Volume I: Orientação a Professores. Ministério da Educação. Secretaria de Educação Especial. Brasília.

DREYER, J. Infância Superdotada: um olhar sobre a constituição de si, das crianças participantes de um grupo de altas habilidades. 20I4. I30 f. Dissertação (Mestrado em Educação) - Universidade Federal do Rio Grande do Sul. Porto Alegre. 20I4. Disponível em: <https://lume.ufrgs.br/handle/I0I83/III9I0>. Acesso em: II fev. 202 I

ESCOBAR, Herton. Fábricas de conhecimento: $O$ que são, como funcionam e para que servem as universidades públicas de pesquisa. 2019. Disponível em: <https://jornal.usp.br/ciencias/fabricas-deconhecimento/.>. Acesso em: 08 mar. 2021

FERNANDES, G. S. Entre uma sala e outra: uma experiência etnográfica a partir das salas de recursos para altas habilidades/Superdotação em Porto Alegre, Rio Grande do Sul. 20I I. I 58 f. Dissertação (Mestrado em Antropologia Social). Universidade Federal do Rio Grande do Sul. Porto Alegre. 20II. Disponível em: <https://lume.ufrgs.br/handle/I0I83/49II3>. Acesso em: II fev. 202I

FLEITH, Denise de Souza (Org.) A construção de práticas educacionais para alunos com altas habilidades/superdotação. Vol. 3. Brasília: Ministério da Educação, Secretaria de Educação Especial, 2007.

GARDNER, Howard. Estruturas da mente: a Teoria das Inteligências Múltiplas. Porto Alegre: Artes Médicas, 1994.

GARDNER, Howard. Inteligências múltiplas: a teoria na prática. Porto Alegre: Artes Médicas, 2000.

GUIMARÃES, Tânia Gonzaga; OUROFINO, Vanessa Terezinha Alves Tentes. Estratégias de Identificação do Aluno com Altas Habilidades/ Superdotação. In: FLEITH, Denise de Souza. A

Construção de Práticas Educacionais para Alunos com Altas Habilidades I

Superdotação: Volume I - Orientação a Professores. Brasília: Ministério da Educação, Secretaria de Educação Especial, 2007. cap. 4, p. 53-65. Disponível em:

<http://portal.mec.gov.br/seesp/arquivos/pdf/altashab2.pdf.> Acesso em: 10 maio 202I.

KLAGENBERG, R. M. Altas Habilidades/Superdotação: O que se faz nas Salas de Recursos Multifuncionais na Rede Municipal de Ensino de Canoas/RS. 20I4. II 4 f. Dissertação (Mestrado em Educação) - Centro Universitário La Salle. Canoas, 20I4. Disponível em:

<http://hdl.handle.net/I 1690/922>. Acesso em: II fev. 202 I

LIMA, D. M. M. P.; BRANDÃO, S. H. A. O atendimento educacional especializado para alunos com altas habilidades e superdotação. In: MORI, Nerli Nonato Ribeiro; JACOBSEN, Cristina Cerezuela (Org.). Atendimento educacional especializado no contexto da educação básica. Maringá: EDUEM, 2012. Cap. II, p. I40-I5I.

LYRA, J. C. Atendimento Educacional Especializado de Alunos com Altas Habilidades/Superdotação na cidade de Londrina, Paraná. 20I3. I52 f. Dissertação (Mestrado em Educação) - Universidade Estadual de Londrina. Londrina. 2013. Disponível em: <http://www.bibliotecadigital.uel.br/document/?code=vtls000 186170>. Acesso em: II fev. 202 I 
OLIVEIRA, D. C. N. O Núcleo de Atividades de Altas Habilidades/Superdotação da cidade de Manaus (NAAH/S): Desafios e perspectivas. 2017. 8I f. Dissertação (Mestrado em psicologia) Universidade Federal do Amazonas. Manaus. 2017. Disponível em:

<https://tede.ufam.edu.br/handle/tede/5898>. Acesso em: II fev. 202I.

PÉREZ, S. G. P. B. Sobre perguntas e conceitos. In: FREITAS, S. N. (Org.). Educação e altas habilidades/superdotação: a ousadia de rever conceitos e práticas. Santa Maria: Ed. da UFSM, 2006, p. 37-60.

PÉREZ, S. G. P. B.; FREITAS, S. N. Encaminhamentos pedagógicos com alunos com Altas Habilidades/ Superdotação na Educação Básica: o cenário brasileiro. Educar em Revista, Curitiba, n. 4I, p. 109124, 20 I I. Disponível em: <https://www.scielo.br/pdf/er/n4 I/08.pdf>. Acesso em: I 2 fev. 202 I

RECH, A. J. D. A organização do Atendimento Educacional Especializado para o aluno com Altas Habilidades/Superdotação. In: PAVÃO, A. C. O; PAVÃO, S. M. O; NEGRINI, T. (org.).

Atendimento educacional especializado altas habilidades superdotação. Santa Maria-RS: FACOS-UFSM, 2018. p. 157-184. Disponível em: <https://www.ufsm.br/app/uploads/sites/39|/2019/04/Livro-AHSD-Finalizado-p\%C3\%B3s-prova.pdf.>. Acesso em: 10 fev. 2021 .

RENZULLI, J. S. O que é esta coisa chamada Superdotação, e como a desenvolvemos? Uma retrospectiva de vinte e cinco anos. Revista Educação, Porto Alegre - RS, ano XXVII, n. I (52), p. 75 - I3I, 2004. Disponível em: https://www.marilia.unesp.br/Home/Extensao/papah/o-que-e-estacoisa-chamada-superdotacao.pdf. Acesso em: 10 fev. 2021.

RIFIOTIS, T. Sujeito de direitos e direitos do sujeito. In: SILVEIRA, R.M.G. et al. Educação em Direitos Humanos: fundamentos teórico-metodológicos. João Pessoa: Editora Universitária, 2007, Pp.23I-244.

ROMANOWSKI, J. P.; ENS, R. T. As pesquisas denominadas do tipo - estado da arte. Diálogo Educacional, Curitiba, v. 6, n. 19, p. 37-50, set. 2006. Disponível em: $<$ https://periodicos.pucpr.br/index.php/dialogoeducacional/article/view/24l7>. Acesso em: 20 set. 2020

VIEIRA, S. M. M. O Atendimento Educacional Especializado para Altas Habilidades/ Superdotação na rede pública estadual do NRE de Cascavel - PR: das Políticas à Prática. 2020. 168 f. Dissertação (Mestrado em Educação) - Universidade Estadual do Oeste do Paraná. Cascavel. 2020. Disponível em: <http://tede.unioeste.br/handle/tede/5206>. Acesso em: II fev. 202 I

VIRGOLIM, A. M. R. A identificação de alunos para programas especializados na área das altas habilidades/superdotação: problemas e desafios. Revista brasileira de altas habilidades/superdotação, Porto Alegre, v. I, n. I, 20I3. Disponível em: $<$ https://conbrasd.org/docs/2_PUBLICACAO/REVISTAS/REVISTA_N_I.PDF> Acesso em: 12 fev. 2021. 
Recebido em: 03 de julho de 2021 .

Versão corrigida recebida em: 08 de setembro de 2021.

Aceito em: 08 de setembro de 2021.

Publicado online em: 03 de dezembro de 2021.

(c) (1) 